\title{
Underdiagnosis and undertreatment of migraine in Poland
}

\author{
Olga P. Fermo \\ Department of Neurology, Mayo Clinic, Jacksonville, Florida, USA
}

(Neurol Neurochir Pol 2021; 55 (4): 331-332)

'Migraine without aura' is defined as recurrent long-lasting (4-72 hours) headache attacks which display at least two of the following four characteristics: unilateral location, a pulsating quality, moderate or severe pain intensity, and/or aggravation by routine activity. This must be accompanied by additional symptoms during the attack, specifically nausea and/or vomiting or photophobia and phonophobia [1].

'Migraine with aura' is diagnosed when a migraine headache is accompanied by stereotypical attacks of gradual, fully reversible, visual, sensory, language, motor, brainstem or retinal symptoms typically lasting between five minutes and one hour [1].

An individual is said to have 'chronic migraine' when headaches occur on at least 15 days a month for more than three months, and when the headache displays the previously defined features of migraine on at least eight days each month [1].

The term 'episodic migraine' is used when headaches occur on 14 or fewer days per month.

Migraine is one of the most common disorders, estimated to affect 1.04 billion people worldwide, with a global prevalence of $14.4 \%$ in adults [2]. Lifetime prevalence in Poland has been reported to be $10 \%$ [3]. Migraine not only limits activity during the ictal phase but also causes disability between attacks, for example by causing anticipatory anxiety. This disability, when taken together with the particularly high prevalence during the working-age decades of life, and the inherent, lifelong nature of the disorder, accounts for migraine being the second leading cause of years lived with disability [4].

Given the high disability associated with migraine attacks, all patients should be offered acute (as-needed) treatment [5]. Optimal acute treatment should provide pain freedom at 2 hours without the need for rescue medication, and should sustain that response over the next 46 hours. These are the currently used benchmarks in migraine drug development, and the same goals should translate into clinical practice $[5,6]$. The American Headache Society published an evidence-based assessment of acute treatments in 2015, with all six available triptans and ergots (termed migraine-specific treatments because of their action on the trigeminovascular calcitonin gene-related peptide (CGRP) pathway) demonstrating Level A evidence [5, 7].

Since late 2019, three additional migraine-specific acute treatments have joined the commercial market: lasmiditan, ubrogepant and rimegepant, further expanding the armoury of efficacious, safe, well-tolerated treatments [8-10]. The choice of specific agent depends on the attack characteristics. It is recommended to tailor the formulation (oral, intranasal, or subcutaneous), onset of action and duration of action of the drug to the time of migraine attack (morning attacks being typically more severe), time to peak headache intensity, degree of associated nausea and vomiting, typical duration of attack, and frequency of recurrence [5]. An inappropriately or incompletely treated attack risks increasing the number of attacks over time or making the attacks more severe [11].

The American Migraine Prevalence and Prevention Study, a large epidemiological summary of the US prevalence, burden, and treatment patterns of migraine, found that nearly $40 \%$ of migraineurs were candidates to receive prevention therapy for migraine, but only $12.4 \%$ were currently using a preventive treatment. Since the chances of developing chronic migraine greatly increase with escalating episodic migraine frequency, patients with frequent migraine should be offered preventive treatment to keep attack frequency low $[12,13]$. Prevention is not necessary when attack frequency is low (i.e. three or fewer days per month) and disability is low. Prevention should be offered when attack frequency is $6+$ days per month, regardless of associated disability, and should be considered when the frequency is lower but some level of impairment is present [12]. There are numerous available treatments with established efficacy for prevention, in particular since the commercial arrival in 2018 of CGRP monoclonal antibodies [14, 15].

Migraine-specific acute treatment, and preventive treatment, can only be offered when migraine is clinically recognised. Despite its high prevalence, migraine is significantly under-recognised by both patients and physicians in Europe [16]. 
In this issue of PJNNS, Domitrz et al. have conducted a survey of general practitioners (GPs) in Poland to assess their treatment habits. They found that only $10 \%$ of GPs could correctly define migraine without aura according to the fully published criteria, and only $18 \%$ correctly distinguished episodic from chronic migraine [17]. This gap in knowledge implies that a sizeable proportion of Polish migraineurs are not being offered migraine-specific acute or preventive treatment. Indeed, most GPs in this group did not prescribe prevention for episodic migraine, and only $18 \%$ were aware that monoclonal antibodies were available for use in Poland [17].

Moreover, these results highlight only part of the problem, given the recent demonstration that the majority of surveyed neurologists in Poland also could not provide the exact diagnostic criteria for migraine [18].

The study by Domitrz et al. is another demonstration of all-too-common gaps in the understanding and treatment of migraine, a frequently encountered debilitating lifelong disorder. This should serve as a wake-up call for educational and awareness campaigns.

\section{References}

1. Olesen J. The International Classification of Headache Disorders, 3rd edition. Cephalagia. 2013; 33(9): 629-808.

2. Stovner L, Nichols E, Steiner TJ, et al. Global, regional, and national burden of migraine and tension-type headache, 1990-2016: a systematic analysis for the Global Burden of Disease Study 2016. Lancet Neurol. 2018; 17(11): 954-976, doi: 10.1016/S14744422(18)30322-3, indexed in Pubmed: 30353868.

3. Stępień A, Prusiński A, Suwa A, Klinika Neurologii Uniwersytetu Medycznego K, Pfizer Polska. Wybrane Dane Epidemiologiczne Występowania Migreny w Polsce (Selected Epidemiological Data on Migraine Prevalence in Poland).

4. Burch RC, Buse DC, Lipton RB. Migraine: Epidemiology, Burden, and Comorbidity. Neurol Clin. 2019; 37(4): 631-649, doi: 10.1016/j. ncl.2019.06.001, indexed in Pubmed: 31563224.

5. Tepper SJ. Acute Treatment of Migraine. Neurol Clin. 2019; 37(4): 727 742, doi: 10.1016/j.ncl.2019.07.006, indexed in Pubmed: 31563229.

6. Tfelt-Hansen P, Pascual J, Ramadan N, et al. International Headache Society Clinical Trials Subcommittee. Guidelines for controlled trials of drugs in migraine: third edition. A guide for investigators. Cephalalgia. 2012; 32(1): 6-38, doi: 10.1177/0333102411417901, indexed in Pubmed: 22384463.

7. Marmura MJ, Silberstein SD, Schwedt TJ. The acute treatment of migraine in adults: the american headache society evidence assessment of migraine pharmacotherapies. Headache. 2015; 55(1): 3-20, doi: 10.1111/head.12499, indexed in Pubmed: 25600718.

8. Kuca B, Silberstein SD, Wietecha L, et al. COL MIG-301 Study Group. Lasmiditan is an effective acute treatment for migraine: A phase 3 randomized study. Neurology. 2018; 91(24): e2222-e2232, doi: 10.1212/WNL.0000000000006641, indexed in Pubmed: 30446595.

9. Dodick DW, Lipton RB, Ailani J, et al. Ubrogepant for the Treatment of Migraine. N Engl J Med. 2019; 381(23): 2230-2241, doi: 10.1056/ NEJMoa1813049, indexed in Pubmed: 31800988.

10. Croop R, Lipton RB, Kudrow D, et al. Rimegepant, an Oral Calcitonin Gene-Related Peptide Receptor Antagonist, for Migraine. N Eng| J Med. 2019; 381(2): 142-149, doi: 10.1056/NEJMoa1811090, indexed in Pubmed: 31291516.

11. Lipton RB, Fanning KM, Serrano D, et al. Ineffective acute treatment of episodic migraine is associated with new-onset chronic migraine. Neurology. 2015; 84(7): 688-695, doi: 10.1212/ WNL.0000000000001256, indexed in Pubmed: 25609757.

12. Lipton RB. Bigal ; M E, Diamond ; M, Freitag ; F, Reed ML, Stewart WF. Migraine Prevalence, Disease Burden, and the Need for Preventive Therapy. ; 2007.

13. Katsarava Z, Schneeweiss S, Kurth T, et al. Incidence and predictors for chronicity of headache in patients with episodic migraine. Neurology. 2004; 62(5): 788-790, doi: 10.1212/01.wnl.0000113747.18760.d2, indexed in Pubmed: 15007133.

14. Silberstein SD, Holland S, Freitag F, et al. Quality Standards Subcommittee of the American Academy of Neurology and the American Headache Society. Evidence-based guideline update: pharmacologic treatment for episodic migraine prevention in adults: report of the Quality Standards Subcommittee of the American Academy of Neurology and the American Headache Society. Neurology. 2012; 78(17): 1337-1345, doi: 10.1212/WNL.0b013e3182535d20, indexed in Pubmed: 22529202.

15. Parikh SK, Silberstein SD. Preventive Treatment for Episodic Migraine. Neurol Clin. 2019; 37(4): 753-770, doi: 10.1016/j.ncl.2019.07.004, indexed in Pubmed: 31563231.

16. Katsarava Z, Mania M, Lampl C, et al. Poor medical care for people with migraine in Europe - evidence from the Eurolight study. J Headache Pain. 2018; 19(1): 10, doi: 10.1186/s10194-018-0839-1, indexed in Pubmed: 29392600.

17. Domitrz I, Lipa A, Rożniecki JJ, et al. Migraine diagnosis and treatment in Poland: survey of primary care practitioners. Neurol Neurochir Pol. 2021, doi: 10.5603/PJNNS.a2021.0045.

18. Domitrz I, Lipa A, Rożniecki J, et al. Treatment and management of migraine in neurological ambulatory practice in Poland by indicating therapy with monoclonal anti-CGRP antibodies. Neurol Neurochir Pol. 2020; 54(4): 337-343, doi: 10.5603/PJNNS.a2020.0054, indexed in Pubmed: 32687594. 